\title{
Helicopter Performance and Vibration Enhancement by Twist-Actuated Blades
}

\author{
SangJoon Shin* and Carlos E. S. Cesnik ${ }^{\dagger}$ \\ Department of Aerospace Engineering \\ University of Michigan, Ann Arbor, Michigan
}

\begin{abstract}
This paper investigates potential improvements that can be accomplished by integral twist-actuated rotor blades regarding helicopter performance and its vibration. The twist deformation is obtained using anisotropic piezocomposite actuators embedded in the composite blade construction. A four-bladed fullyarticulated Active Twist Rotor (ATR) system was built and tested at Langley Transonic Dynamics Tunnel. From these tests, the integral twist control authority exerted upon the fixed system was determined. Significant control authority in hub vertical shear load component is observed from different blade actuation modes. Similar control authority is found in the other components of the fixed-system loads. Exploiting those authorities, vehicle performance enhancement can be achieved using low-frequency actuation, for example, $0 \mathrm{P}, 1 \mathrm{P}$ and 2P. Payload increase in hover can be obtained with a steady collective actuation of blade twist. Power consumption can be reduced by employing a certain mode of blade actuation at $2 \mathrm{P}$ in forward flight. Vehicle pitch and roll moments are generated by longitudinal and lateral blade actuation mode at $1 \mathrm{P}$ frequency. On the other hand, actuation at higher frequencies can be used to reduce hub vibratory loads. The closed-loop control algorithm used for this reduction is an improved version of the traditional Higher Harmonic Control. Multiharmonic and multi-mode controller is designed and tested as part of the present study.
\end{abstract}

\section{INTRODUCTION}

Rotorcraft has been a very important means of aerial transportation due to its capability of vertical take-off and landing. However, it has also been under

\footnotetext{
*Post-doctoral Research Fellow. Member, AIAA. Member, AHS.

${ }^{\dagger}$ Associate Professor of Aerospace Engineering. Associate Fellow, AIAA. Member, AHS.

Copyright(C)2003 by SangJoon Shin and Carlos E. S. Cesnik. Published by the American Institute of Aeronautics and Astronautics, Inc., with permission.
}

serious constraints such as relatively poor ride quality associated with high levels of vibration and noise, restricted flight envelope, low fatigue life of the structural components, and consequently high operating cost. The primary source which brings these shortcomings is the complex unsteady aerodynamic environment generated near the rotor blades mainly during forward flight. An instantaneous asymmetry of the aerodynamic loads acting on the blade at different azimuth locations is developed, and such asymmetry becomes more and more adverse as the forward flight speed increases. Such an unsteady aerodynamic environment near the rotor system also imposes constraints on the vehicle performance.

There have been considerable efforts in the helicopter community to improve helicopter performance and vibration, and most of them are based on passive methodologies [1]. During the last two decades, however, active methods to alleviate helicopter vibration based on the idea of directly modifying the unsteady aerodynamic loads on the rotor blades have been pursued. These methods may be broadly classified as higher harmonic control and individual blade control $[2,3]$. Higher harmonic control (HHC) is accomplished by manipulating a conventional swashplate to enable blade pitch control at a higher multiple frequency than integral multiple of the rotor rotating frequency, i.e., $(k N \pm 1) / \mathrm{rev}[2,4,5,6,7,8]$. Classical individual blade control (IBC) uses a feathering actuator in each blade rather than modulating the swashplate, and allows for blade pitch control at arbitrary frequencies [3, 9]. Several outstanding results were obtained in terms of vehicle performance and vibration improvement. Examples include wind tunnel tests with either small or full-scaled model $[2,9,10]$, and flight tests [4].

For a closed-loop control implementation based on these methods, the so-called $\mathrm{T}$ matrix approach has been used to identify system transfer functions and determine the design of controllers $[2,5,6]$. In that approach, discrete component at target frequency, i.e., $N \Omega$, among the transfer function was only identified from sine-dwell open-loop actuation and used in the 
controller design. More advanced control algorithms were developed based on the basic $\mathrm{T}$ matrix approach and tested on an experimental rotor system in the wind tunnel. These controllers in general exhibited satisfactory capability for helicopter vibratory load reduction either in fixed-system or rotating-system loads. Flight test on a modified $\mathrm{OH}-6 \mathrm{~A}$ aircraft was also conducted successfully with the higher harmonic control based on the T matrix approach [4]. However, these realizations have shown significant limitations for application in helicopters production. Typical identified problems are adverse power requirement and limitation on excitation frequency in $\mathrm{HHC}$, and extreme mechanical complexity of hydraulic sliprings in IBC.

A variety of actuation mechanisms based on active materials have recently been suggested and tested to overcome the difficulties in the conventional HHC and IBC $[11,12,13]$. These active material-based actuators are embedded or surface-mounted at several locations in rotor blades, or installed inside the blade to drive trailing-edge flaps. By replacing the traditional hydraulic systems with active material-based actuators, potential advantages can be obtained in terms of weight and power consumption. In this study, an integral twist actuation concept is chosen for individual blade control among the various implementations $[14,15]$. Although this implementation results in a different physical configuration than the hydraulic-based ones, its control scheme for improved vehicle performance and vibration may be developed from a common HHC or IBC methodology. A control algorithm based on the $\mathrm{T}$ matrix approach from the conventional $\mathrm{HHC}$ scheme was implemented successfully on an active rotor blade with trailing-edge flap driven by an X-Frame actuator in hover [16]. A similar scheme extended with an optimal control theory was investigated analytically for a possible application on a flap-actuated active rotor system [17].

Regarding vehicle performance improvement, there has been a successful wind-tunnel demonstration of fullscale BO-105 helicopter rotor with traditional IBC actuators [9]. In that experiment, reduced rotor power consumption was achieved during the forward flight by applying a certain prescribed actuation on the feathering actuators, called IBC mode. A preliminary analytical study was conducted on the $\mathrm{CH}-47 \mathrm{D}$ helicopter with integrally twist-actuated rotors [18]. An increase of hover payload was predicted using a steady blade actuation in that study.

NASA/Army/MIT Active Twist Rotor (ATR) program has been investigating the integral blade twist actuation for helicopter vibration in a more comprehen- sive fashion. It is a collaborative research effort between the U.S. Army Research Laboratory, at NASA Langley Research Center, and the University of Michigan/MIT. Throughout this program, analysis and design capabilities were established for active blades with embedded anisotropic piezocomposite actuators [19]. Using those capabilities, a prototype ATR blade was designed and fabricated for bench and hover tests [20, 21, 15]. After minor design modification, new ATR blades were manufactured and tested in forward flight [15]. During the open-loop forward flight test, significant changes on both fixed- and rotating-system loads were observed from a prescribed blade twist actuation [15]. This culminates to tests demonstrating the vibratory load reduction capability of the ATR concept and the control laws.

This paper evaluates the active blade twist control authority for improvements in vehicle performance and vibration. System identification is conducted experimentally to estimate the harmonic transfer functions [22] of the ATR system in various forward flight conditions. Sine-sweep input signals with varying control phase angles are used with several modes of blade actuation: collective, longitudinal cyclic, lateral cyclic, and differential. From those results, blade twist control authority on the rotor fixed-system can be determined. This control authority can also be translated into additional force (thrust) or moment that the rotor system can generate at a given frequency. Payload increase in hover, rotor power reduction in forward flight, and hub vibratory load reduction are considered here.

\section{FRAMEWORK}

For analyzing helicopter blades with embedded strain actuators, a framework is needed such that the effects of the active material embedded in the structure are carried throughout all the steps of the analysis. Since there are few analysis formulations available which can properly handle all the peculiarities of an active helicopter blade cross section like the ATR, the authors have worked on creating a general framework for active rotor blade modeling. Here, an asymptotical analysis takes the electromechanical three-dimensional problem and reduces it into a set of two analyses: a linear analysis over the cross section and a nonlinear analysis of the resulting beam reference line. By coupling the active blade formulation with the appropriate unsteady aerodynamics, the aeroelastic problem can then be solved in time and simulations be conducted for control design. A schematic diagram of the established framework is shown in Fig. 1. 


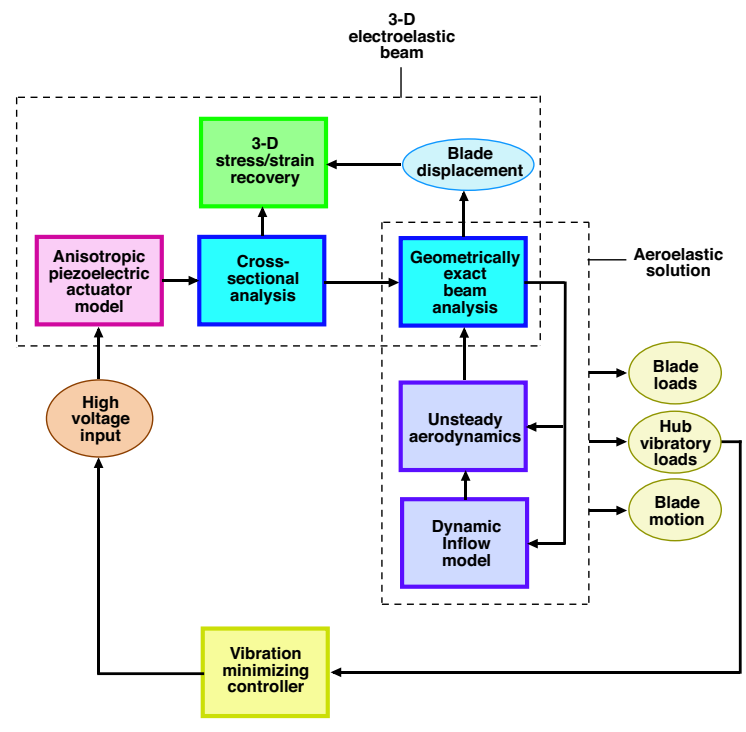

Figure 1: Schematic diagram of the analytical framework for an active helicopter blade and its aeroelastic behavior

\section{Cross-Sectional Analysis}

Stiffness and actuation forcing constants for an active anisotropic thin-walled two-cell beam are obtained from a variational-asymptotical formulation [19]. While restricted to thin-walled beams, it yields closed form solutions of the displacement field (which is derived and not assumed), and stiffness and actuation constants. The availability of correct closed form expressions is essential to determine design paradigms on this new type of blade, mainly concerning the tradeoffs between torsional stiffness and twist actuation. These stiffness and actuation constants are then used in the beam finite element discretization of the blade reference line.

\section{Blade Structure and Aerodynamic Analyses}

To simulate the active rotor system, a time domain formulation is needed. The multi-body dynamics code DYMORE, developed by Bauchau and co-workers [23], is based on the geometrically-exact beam equations and it is coupled to the aerodynamics of Peters and He [24]. DYMORE's original beam formulation is consistent with the one used previously by the authors in studying hover response of the ATR system [21]. The difference now is that the formulation is displacementbased instead of mixed-form. Therefore, the same crosssectional analysis for active beams can be used. The integral actuation forces and moments existing inside the blade structure are realized in the form of finite element loads to the passive beam in the modified time domain analysis. The solution of the 1-D beam analy- sis provides blade displacement and generalized stress fields due to external loading and piezoelectric actuation, which are of interest in the analysis of static and dynamic deformations and aeroelastic stability.

The forward flight part of the finite-state dynamic inflow aerodynamics model [24] was already implemented in DYMORE. This aerodynamic theory was originally developed for both hover and forward flight conditions. This model was constructed by applying the acceleration potential theory to the rotor aerodynamics problem with a skewed cylindrical wake. More specifically, the induced flow at the rotor disk was expanded in terms of modal functions. As a result, a three-dimensional, unsteady induced-flow aerodynamics model with finite number of states was derived in time domain. This model falls on an intermediate level of wake representation between the simplest momentum and the most complicated free wake methodologies. It does not require a severe computational effort, which is usually the case in those that involve the vortex filament theory. Therefore, this model is applicable to the problems of rotor aeroelastic stability, basic blade-passage vibrations, and higher-harmonic control studies [24].

\section{Aeroelastic System in Forward Flight}

The aeroelastic system of equations which combines the structural and aerodynamic equations obtained in the previous steps is now solved for forward flight condition to provide the information regarding the transient response. Specifically, the present analysis adopts a direct time integration of the blade response due to an integral actuation during flight. This time integration is required since further analytical tasks are expected to conduct in time domain. DYMORE, the original passive blade dynamics model, adopts a timediscontinuous integration scheme with energy decaying characteristics in order to avoid high frequency numerical oscillation [23]. Such an adverse high frequency oscillation usually occurs during a finite element time integration of a complex multi-body dynamic system.

\section{ATR CHARACTERISTICS}

Table 1 summarizes the general dimension and shape characteristics of the ATR blade. The ATR blade employs a total of 24 active fiber composite (AFC) packs placed on the front spar, and distributed in 6 stations along the blade span [15]. Fig. 2 shows basic blade planform and cross section characteristics selected for the ATR prototype blade. The material properties of the passive prepregs and the AFC plies used in the blade are summarized in the appendices of Refs. [19] and [21]. 
Table 1: Characteristics of the ATR blade

\begin{tabular}{||c|c||}
\hline Rotor type & $\begin{array}{c}\text { Fully } \\
\text { articulated }\end{array}$ \\
Number of blades, $b$ & 4 \\
Blade chord, $c$ & $10.77 \mathrm{~cm}$ \\
Blade radius, $R$ & $1.397 \mathrm{~m}$ \\
Solidity, $b c / \pi R$ & 0.0982 \\
Airfoil section & NACA 0012 \\
Blade pretwist & $-10^{\circ}$ \\
Hinge offset & $7.62 \mathrm{~cm}$ \\
Lock number & 9.0 \\
Tip Mach number & 0.6 \\
Centrifugal loading at tip & $738.5 \mathrm{~g}$ \\
Rotor speed & $687.5 \mathrm{rpm}$ \\
Mass per unit span $(\mathrm{kg} / \mathrm{m})$ & 0.6968 \\
1st torsion frequency @ $687.5 \mathrm{rpm}$ & $6.97 / \mathrm{rev}$ \\
\hline
\end{tabular}

\section{SYSTEM IDENTIFICATION TEST}

During forward flight, the helicopter rotor blades are subject to an aerodynamic environment which varies itself with a period corresponding to the rotor revolution. This makes the helicopter rotor a linear timeperiodic system during forward flight. Therefore, a methodology considering this periodicity is required for its characterization. In this paper, a method is adopted which results in multi-component harmonic transfer functions [25]. The theoretical background of the adopted methodology and its implementation schemes are described in detail in [25] including additional assumptions imposed on the transfer functions.

Sinusoids are used to determine transfer functions, and more specifically, sine-sweep waves (chirp signals) are used to obtain the system response over a specific range of frequencies. For each test condition, steadystate equilibrium is established first by adjusting the blade trim pitch controls. Sine-sweep signals corresponding to several modes of blade actuation, such as collective, longitudinal cyclic, lateral cyclic, and differential, are generated with varying initial control phase angles. Then, fixed- and rotating-system responses of the ATR system are measured while applying the constructed sine-sweep input signal. Before applying the system identification algorithm suggested in [25], undesirable noise is removed from the acquired measured data using a simple smoothing algorithm. Then, the amplitude of the baseline loads must be subtracted from those under actuation. The amount of loads added to the baseline quantity becomes the object of a transfer relationship. Five harmonic transfer functions are estimated, i.e., $G_{-2}, G_{-1}, G_{0}, G_{+1}, G_{+2}$, at a given
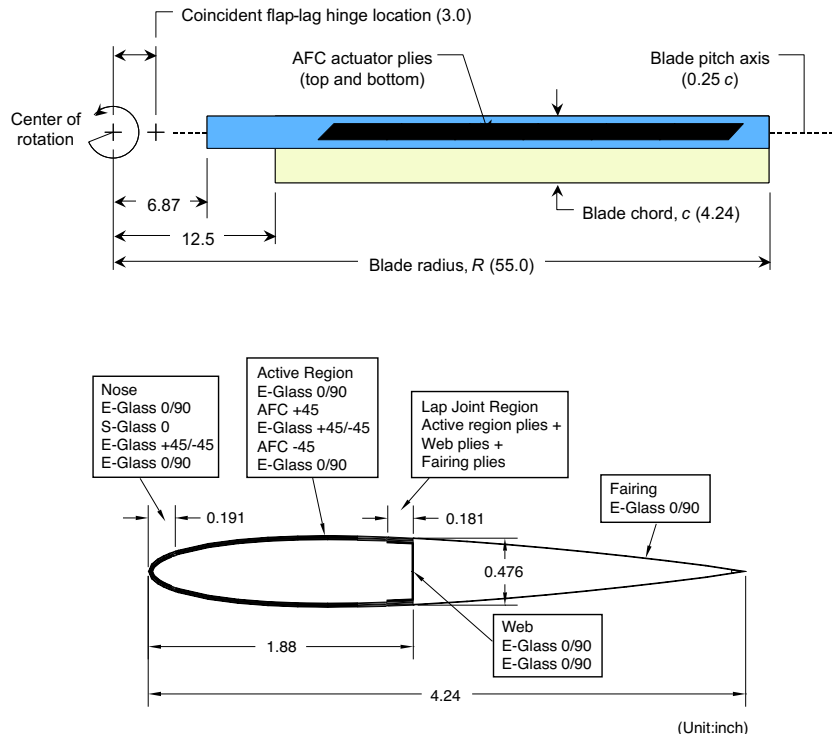

Figure 2: Planform and cross section of the ATR prototype blade (Dimensions are in inches.)

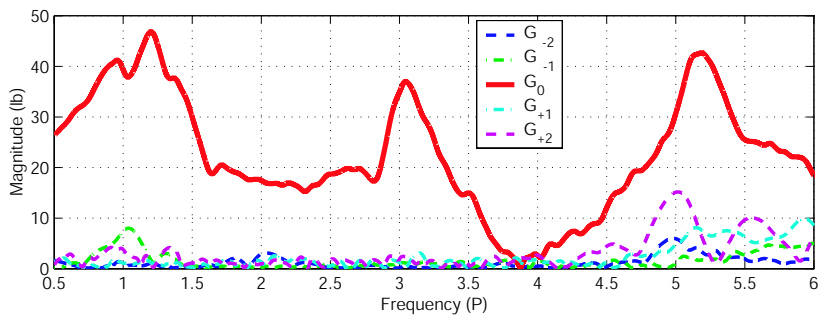

Figure 3: Harmonic transfer functions (magnitude only) of the hub vertical shear loads during collective actuation $\left(\mu=0.333, \alpha_{S}=-6^{\circ}, C_{T}=0.0066\right.$, and $1,000 \mathrm{~V}$ twist actuation)

\section{condition.}

Five harmonic transfer functions estimated for the hub vertical shear load component under collective mode of blade actuation are illustrated in Fig. 3. For the collective mode of actuation, $G_{0}$ is found to have amplitude which is significantly larger compared with the others. This indicates that the response of the ATR system may be described only by the $G_{0}$ component, like in a linear time-invariant (LTI) system, under the flight condition and blade actuation mode considered. The other modes of actuation exhibit a similar result with larger magnitude in $G_{0}$ as well. Differential mode is excluded from further consideration since it theoretically involves null control authority. Therefore, the fundamental transfer functions, i.e., $G_{0}$, obtained for the hub vertical shear load component by three blade modes of 

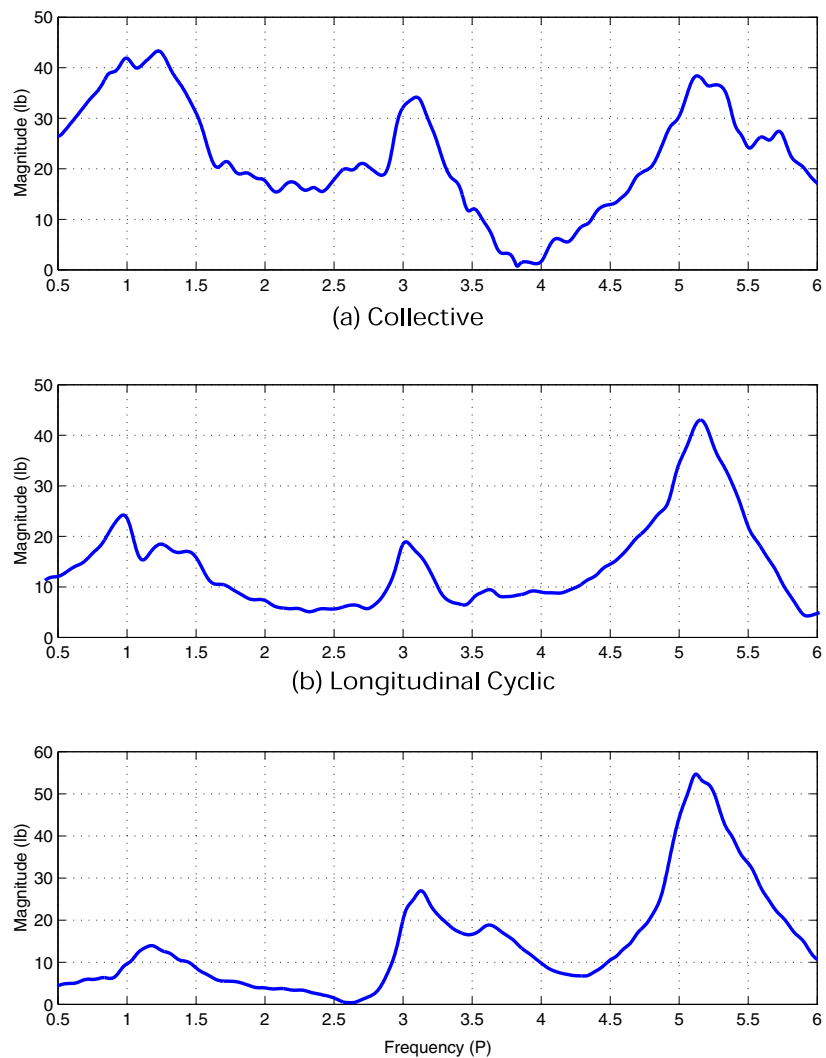

(c) Lateral Cyclic

Figure 4: $G_{0}$ transfer functions (magnitude only) of the hub vertical shear loads for three different modes of actuation $\left(\mu=0.333, \alpha_{S}=-6^{\circ}, C_{T}=0.0066\right.$, and $1,000 \mathrm{~V}$ twist actuation)

actuation are summarized in Fig. 4.

From the harmonic transfer function results, closed-loop controllers can be designed. Since the identified plant can be treated as a LTI system, controllers based on modern control theory methods may be developed. This makes the controller design and preliminary evaluation more effective. Actuation frequency and blade actuation mode used in the control study are selected based on the magnitude and phase of the corresponding transfer function. Also, combination of multiple modes or frequencies must be considered for further performance and vibration enhancement, which results in multi-harmonic or multi-mode controllers.

\section{PERFORMANCE ENHANCEMENT}

Significant control authority, as observed from the magnitude of the transfer functions of Fig. 4, indicates
Table 2: ATR hover payload improvement results

\begin{tabular}{||c|c|c|c||}
\hline & Baseline & $\begin{array}{c}\text { Steady } \\
\text { actuation } \\
(1,000 \mathrm{~V}, \\
\left.8^{\circ} \text { Coll. }\right)\end{array}$ & $\begin{array}{c}\text { Steady } \\
\text { actuation } \\
(1,000 \mathrm{~V}, \\
\left.7.3^{\circ} \text { Coll. }\right)\end{array}$ \\
\hline $\begin{array}{c}\text { Thrust } \\
(\mathrm{N})\end{array}$ & 940 & $\begin{array}{c}1,048 \\
(11.5 \% \text { inc. })\end{array}$ & 940 \\
\hline $\begin{array}{c}\text { Torque } \\
(\mathrm{N}-\mathrm{m})\end{array}$ & 105.6 & 121.9 & 106.3 \\
\hline
\end{tabular}

availability of twist actuation for different potential applications. Improvement in terms of vehicle performance is examined first. By applying steady collective actuation, additional thrust can be generated in hover condition. From Fig. 4 (a), it is expected by extrapolation that approximately $25 \mathrm{lb}$ of the hub vertical shear load is obtained by collective actuation at 0P. This amount of additional thrust is equal to about $10 \%$ of the ATR nominal thrust. Similar thrust variation was predicted by analytical simulation conducted on the Mach-scaled CH-47D active integral twist rotor [18].

Results on the ATR hover payload improvement are provided in Table 2 from numerical simulation developed in [21]. As shown in the second column in Table 2, approximately $11.5 \%$ increase of thrust is obtained when steady twist actuation is applied to the ATR blades in hover. This level of thrust increase coincides with the prediction that was made based on the transfer function results. However, there is no significant advantage observed in rotor power consumption when adjusting the collective pitch to give the same thrust as in the baseline (shown in the third column of Table 2). Steady twist actuation is expected to modify the blade twist distribution from the built-in twist. Even though it should have a potential for net thrust increase, it could not be seen for the ATR.

While no significant advantage is observed using steady actuation in hover, rotor power consumption can be reduced by higher harmonic blade actuation in forward flight. In general, rotor stall and the accompanying changes in blade loads determine the limit to forward flight speed of helicopters. By employing a combination of longitudinal and lateral cyclic actuation, rotor stall may be postponed. This will result in forward flight performance improvement. The transfer function result in Fig. 4 only illustrates a vibratory component among the ATR hub shear loads or moments response obtained by blade actuation at the respective frequency. Thus it is not straightforward to obtain an estimate 


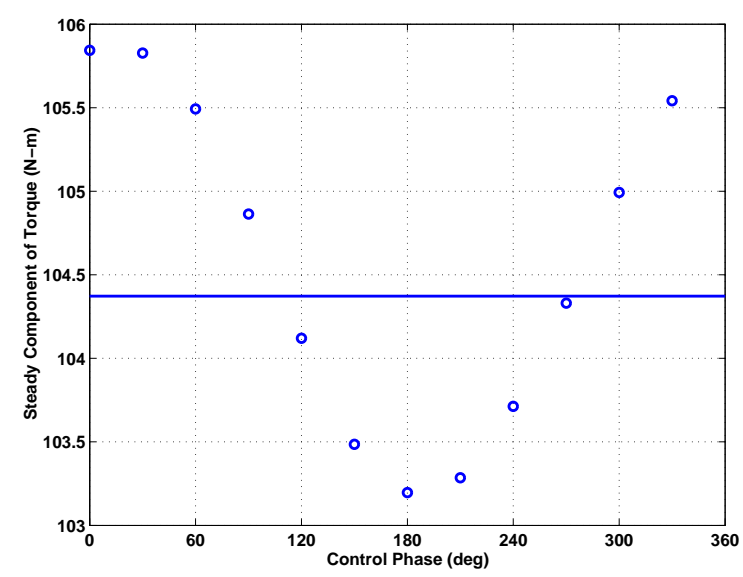

Figure 5: Variation of the ATR hub torque component for $\mu=0.300, \alpha_{S}=-4^{\circ}, C_{T}=0.0066$, and $1,000 \mathrm{~V}$ twist actuation at $2 \mathrm{P}$ with respect to control phase

of how much impact the higher harmonic blade actuation exerts upon a steady component of hub moment, such as torque, from those transfer function results. In the full-scale BO-105 wind-tunnel experiment [9], a prescribed actuation signal (IBC mode) was applied at its feathering actuators to demonstrate a considerable rotor power reduction in forward flight. In this paper, numerical simulation is performed to obtain a preliminary estimate in rotor power consumption from higher harmonic blade actuation based on an IBC signal.

The same IBC mode of blade actuation was exploited during the open-loop control test of the ATR system [15]. In that experiment, $3 \mathrm{P}, 4 \mathrm{P}$, and $5 \mathrm{P}$ IBC mode sine-dwell signals were used, and significant impact on both fixed- and rotating-system vibratory loads was observed. From the numerical simulation on the same open-loop control experiment [26], the predicted trend of load variation with respect to its control phase correlated well between simulation and experiment, although discrepancies were found in the amplitude of

Table 3: ATR forward flight power improvement results

\begin{tabular}{||c|c|c|c||}
\hline & Baseline & $\begin{array}{c}2 \mathrm{P} \text { IBC } \\
\text { actuation } \\
(1,000 \mathrm{~V}, \\
\text { (heavy gas, } \\
\mu=0.300)\end{array}$ & $\begin{array}{c}\text { 2P IBC } \\
\text { actuation } \\
\text { (re-adjusted } \\
\text { trim) }\end{array}$ \\
\hline $\begin{array}{c}\text { Thrust } \\
(\mathrm{N})\end{array}$ & 908 & 923 & 908 \\
\hline $\begin{array}{c}\text { Torque } \\
(\mathrm{N}-\mathrm{m})\end{array}$ & 104.4 & $\begin{array}{c}103.3 \\
(1.0 \% \text { dec. })\end{array}$ & $\begin{array}{c}102.4 \\
(2.0 \% \text { dec. })\end{array}$ \\
\hline
\end{tabular}

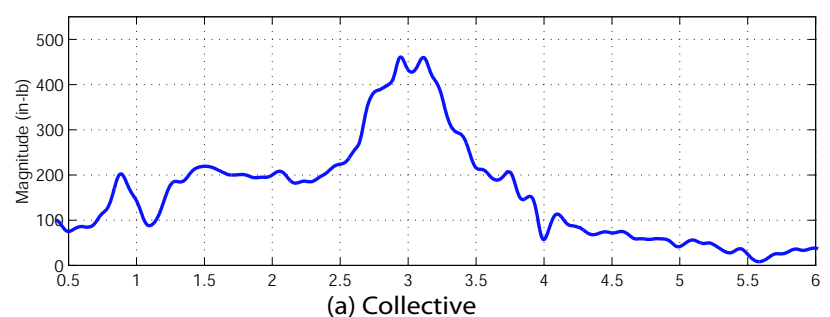

(a) Collective
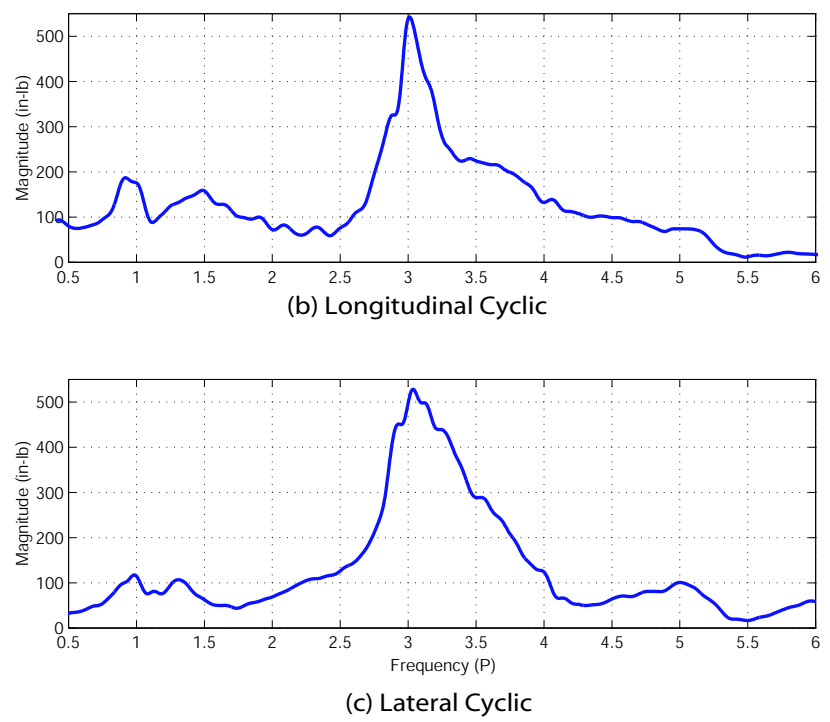

Figure 6: Transfer functions (magnitude only) of the hub pitch moment for three different modes of actuation $\left(\mu=0.333, \alpha_{S}=-6^{\circ}, C_{T}=0.0066\right.$, and $1,000 \mathrm{~V}$ twist actuation)

loads under actuation. In the full-scale BO-105 experiment, various $\mathrm{IBC}$ signals $(2 \mathrm{P}, 3 \mathrm{P}, 4 \mathrm{P}, 5 \mathrm{P}$, and $6 \mathrm{P})$ were used to demonstrate reduction of hub vibratory loads and acoustic noise, but only $2 \mathrm{P}$ IBC signal exhibited a significant advantage in the rotor power consumption. This was due to the more favorable blade angle of attack distribution accomplished by $2 \mathrm{P}$ IBC actuation with a specific control phase. Such 2P IBC actuation is applied to the ATR system in forward flight, and numerical results on its torque variation are plotted in Fig. 5. In this plot, ATR torque obtained at the baseline (no actuation) is illustrated by a horizontal solid line. At the control phase of approximately $180^{\circ}$, the lowest power consumption is obtained. This control phase angle coincides with the angle where the minimum power is observed in the full-scale BO-105 experiment.

However, 2P IBC actuation also alters the other components of the rotor force and moment, as exemplified by the thrust change in the second column of Ta- 
ble 3. To maintain a specified trim condition, the blade pitch control setting needs to be re-adjusted. Results in Fig. 5 are not corrected for that. Table 3 summarizes the baseline and the ones for the $180^{\circ}$ control phase. After re-adjustment to the baseline trim condition, further reduction of rotor power consumption is observed as shown in the third column of Table 3 .

On the other hand, the other IBC signals $(3 \mathrm{P}, 4 \mathrm{P}$, $5 \mathrm{P})$ do not exhibit significant benefit in the ATR rotor power reduction. The power reduction from $2 \mathrm{P}$ IBC is still obtained through the favorable angle of attack distribution, as mentioned previously. As the flight speed increases, blade stall will become a dominating factor in rotor power consumption. $2 \mathrm{P}$ IBC signal is capable of preventing or delaying such blade stall and expected to give an advantage in rotor power reduction in high speed forward flight condition. Since the IBC signal is a combination of the cyclic and collective modes, a closedloop controller similar to the one described later in this paper can accomplish minimum rotor power. This controller will use $2 \mathrm{P}$ collective and cyclic modes of blade actuation, while re-adjusting the blade pitch setting to maintain a desired trim equilibrium.

Significant control authority is observed in the collective mode of blade twist actuation at $1 \mathrm{P}$ frequency for the ATR system. This can be used for blade tracking as discussed in further details in the next section. There, the collective mode of actuation at $1 \mathrm{P}$ is used as a component of a multi-mode closed-loop controller in the ATR vibration tests.

Additional vehicle pitch and roll moment may be generated by applying longitudinal and lateral cyclic modes of blade actuation at steady and $1 \mathrm{P}$ frequency component in combination with the collective mode of actuation. From the ATR system identification test, significant control authority for the vehicle pitch moment is observed from several modes of blade twist actuation. The results are shown in Fig. 6. Here, collective actuation also provides significant vehicle pitching moment due to the forward flight condition. Therefore, it is anticipated that enough vehicle pitching moment can be drawn from the combination of those three modes of blade actuation to assist vehicle's maneuver ability. For vehicle roll moment, similar result can be achieved by the combination of blade actuation modes.

Another important maneuver capability for helicopters, especially military ones, is the "nap-of-theearth (NOE)" [27]. This is associated with the closest flight path when a helicopter flies over obstacles in the ground. For this capability, instantaneous pull-up and push-down thrust generated by the rotor system is re-

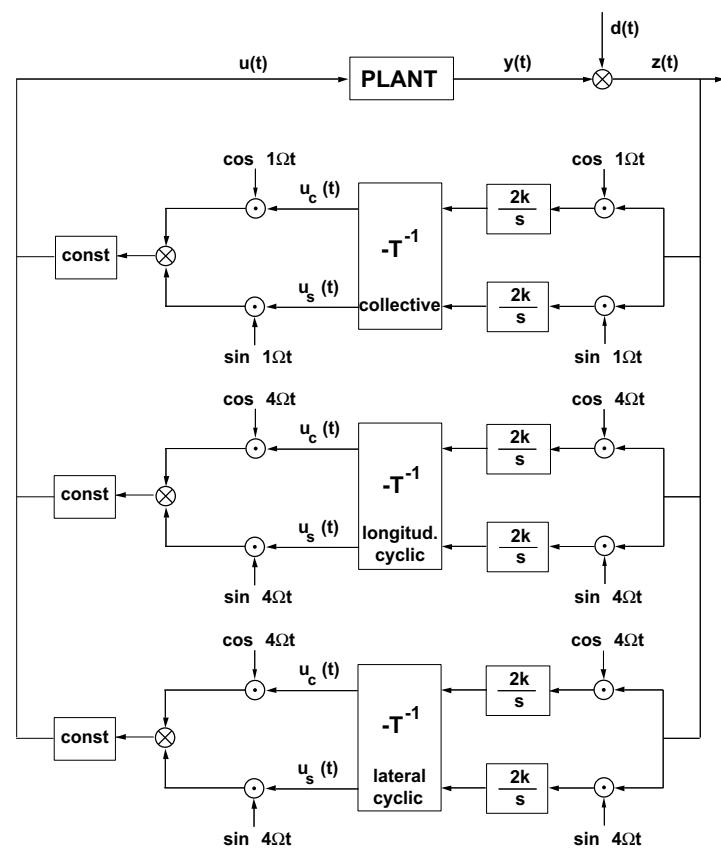

Figure 7: Block diagram of the vibration minimizing controller

quired. Blade twist actuation may be considered to assist this maneuver capability by the combination of the three actuation modes. For upward or downward negative thrust, collective mode of blade action at steady or $1 \mathrm{P}$ frequency is needed. At the same time, to assist vehicle pitching moment in either nose-up before obstacle or nose-down after obstacle, combination of the three blade actuation modes should be considered.

\section{VIBRATION REDUCTION}

While low frequency actuation is used for the vehicle flight performance enhancement, higher harmonic actuation can be used for hub vibratory loads reduction. Its effectiveness for the ATR vibration reduction has already been demonstrated in the open-loop control test [15]. In the ATR system, the primary vibration happens at $4 \mathrm{P}$ since it is a 4-bladed rotor. From Fig. 4, the collective mode of blade actuation is found to have significantly smaller magnitude at $4 \mathrm{P}$ frequency when compared to the two cyclic modes. This renders the collective mode of actuation ineffective for $4 \mathrm{P}$ vibration reduction, and a combination of the cyclic modes at frequencies between $3 \mathrm{P}$ and $5 \mathrm{P}$ is the bases for the controller structure used in this study. On the other hand, the collective mode shows a large control authority at $1 \mathrm{P}$, as mentioned before. Thus, $1 \mathrm{P}$ collective mode is added to the $4 \mathrm{P}$ cyclic modes. Such combination of 


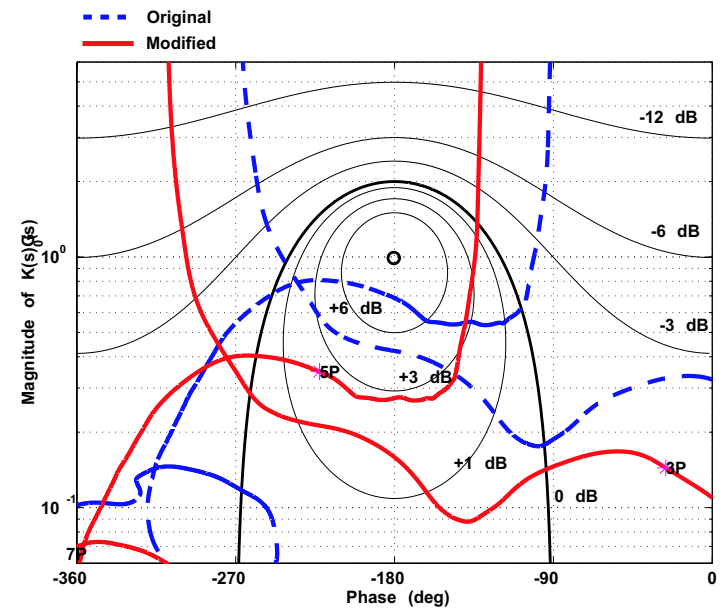

Figure 8: Nichols plot of the loop transfer function with 4P longitudinal cyclic mode controller, original and modified, at $\mu=0.333$

different blade actuation modes at different frequencies results in multi-harmonic and multi-mode structure for the controllers. These controllers are generated by cascading single feedback structure based on the traditional T matrix approach $[2,4,5,6,7,8]$ corresponding to each mode and frequency as shown in Fig. 7. Notice that by controlling the gain of each actuation mode, the total electric field applied to the individual actuators does not exceed their saturation limit.

Before implementing the controllers, the stability of the closed-loop system should be examined. For this purpose, a loop gain, which is a product of the identified plant transfer function, $G_{0}(s)$, and the designed compensator, $K(s)$, is investigated in frequency domain. Since the ATR transfer function was identified with respect to different blade actuation modes, examination of the closed-loop system stability is conducted for each mode. Among the actuation modes included in the controller (Fig. 7), longitudinal cyclic mode at $4 \mathrm{P}$ is exemplified here. Nichols plot of the closed-loop system without any modification on $K(s)$ is displayed as a dashed line in Fig. 8 for the advance ratio condition of $\mu=0.333$. In the same plot, contours of constant disturbance attenuation (or amplification) are also plotted according to the following relation.

$$
\frac{y}{d}=\frac{1}{1+G_{0}(s) K(s)}
$$

where $y$ is the plant output and $d$ is the disturbance, as defined in Fig. 7. To aid in interpreting the level of vibration reduction or amplification, the magnitude of Eq. (1) as a function of frequency is plotted in Fig. 9.

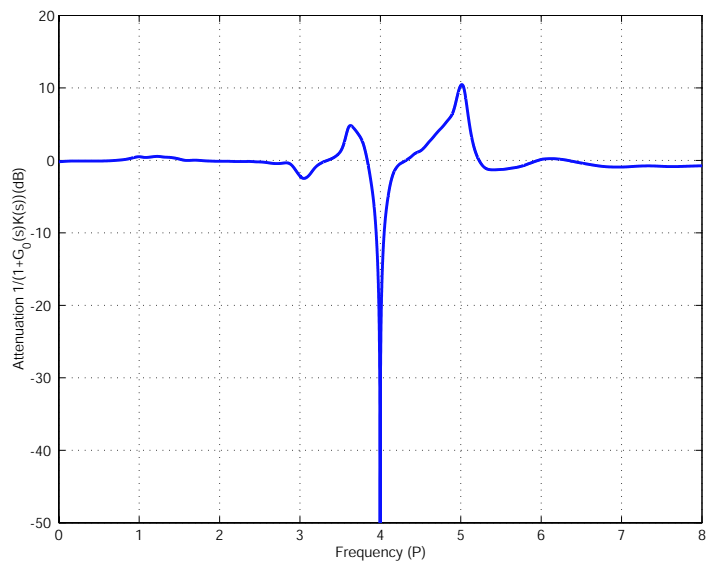

Figure 9: Closed-loop attenuation of the ATR hub vertical vibratory loads with longitudinal cyclic mode actuation at $\mu=0.333$

As expected, there exists a significant reduction of disturbance at the target frequency, 4P. However, in the vicinity of $4 \mathrm{P}$, there also appears undesirable amplification of the disturbance. The amount of the amplification present is related to the stability margin of the control system. According to Fig. 8, the present controller with the unmodified $K(s)$ has a gain margin of approximately $3.2 \mathrm{~dB}$, and phase margin of $70^{\circ}$, a margin regarded sufficient for a general feedback compensator. However, when the gain of the controller is increased, i.e, the closed-loop gain line is shifted upward, the gain margin reduces and a potential instability is nearer. Therefore, a modification on the original controller is desired to improve the gain margin. A solution is to alter the closed-loop gain to have new phase characteristics, that is, shift the phase by $-40^{\circ}$ from its original one. Such modification generates a new plot, which is shown as a solid line in Fig. 8. The other modes of blade actuation used in the controller, i.e., 4P lateral cyclic and $1 \mathrm{P}$ collective modes, are also modified in a similar way to improve controller performance.

Many different combinations of the blade actuation modes were attempted in the closed-loop control test. In each combination, different relative gain constants are assigned for each feedback structure, and tested at different flight conditions. The combinations used in the test are summarized in Table 4. From the transfer function results, relatively high control authority is observed at $1 \mathrm{P}$ for the collective actuation mode. Therefore, a small gain constant, 0.2 , is assigned to $1 \mathrm{P}$ collective mode controller along with relatively larger constants for the cyclic modes. In the three-mode controller, relative gain constants of $(0.2,1.0,1.0)$ for collective, lon- 
Table 4: Assignment of relative gain constants in the vibration reduction test

\begin{tabular}{||c|c|c|c|c||}
\hline $\begin{array}{c}\text { Case } \\
\text { name }\end{array}$ & $\begin{array}{c}1 \mathrm{P} \\
\text { collective }\end{array}$ & $\begin{array}{c}4 \mathrm{P} \\
\text { longi. } \\
\text { cyclic }\end{array}$ & $\begin{array}{c}4 \mathrm{P} \\
\text { lateral } \\
\text { cyclic }\end{array}$ & $\begin{array}{c}\text { Advance } \\
\text { ratio } \\
(\mu)\end{array}$ \\
\hline Cyc1 & 0.0 & 0.0 & 1.0 & 0.333 \\
Cyc2 & 0.0 & 0.5 & 0.5 & 0.333 \\
Cyc3 & 0.0 & 0.707 & 0.707 & 0.333 \\
Cyc4 & 0.0 & 0.9 & 0.9 & 0.333 \\
Cyc5 & 0.0 & 1.0 & 1.0 & 0.333 \\
CollCyc1 & 0.2 & 0.707 & 0.707 & 0.333 \\
CollCyc2 & 0.2 & 0.9 & 0.9 & 0.333 \\
CollCyc3 & 0.2 & 1.0 & 1.0 & 0.333 \\
CollCyc4 & 0.2 & 0.9 & 0.9 & 0.267 \\
CollCyc5 & 0.2 & 1.0 & 1.0 & 0.267 \\
CollCyc6 & 0.2 & 0.9 & 0.9 & 0.200 \\
CollCyc7 & 0.2 & 1.0 & 1.0 & 0.200 \\
CollCyc8 & 0.2 & 0.9 & 0.9 & 0.140 \\
CollCyc9 & 0.2 & 1.0 & 1.0 & 0.140 \\
\hline
\end{tabular}

gitudinal cyclic, and lateral cyclic mode, respectively, provides the maximum allowable electric field in the actuators. Such three-mode controller with the parameters determined from the condition $\mu=0.333$ is also tested at other flight conditions, such as $\mu=0.267$, $0.200,0.140$.

Among the different flight conditions and different gain constant combinations tested, the greatest reduction of $4 \mathrm{P}$ vibration, approximately $40 \mathrm{~dB}$, is obtained at $\mu=0.267$ with the gain combination $(0.2$, $0.9,0.9)$ for the three actuation modes. Significant attenuation of vibratory loads is observed at each discrete integer/rev frequency, and it is summarized in Fig. 10. Since $1 \mathrm{P}$ and $4 \mathrm{P}$ components are included in this specific controller, higher reduction is obtained at these two frequencies.

Since $4 \mathrm{P}$ is the primary frequency of vibration in the ATR, vibration reduction at $4 \mathrm{P}$ is computed and summarized in Table 5. Open-loop and closedloop $4 \mathrm{P}$ peak values are provided in the columns called "open-loop" and "closed-loop" rms (root-mean-square) value. However, due to the slight amplification observed around 4P (see Fig. 9.), a more realistic estimation of vibration reduction is provided by integrating the response spectrum over a short interval around $4 \mathrm{P}$ and comparing the results between open-loop and closedloop conditions. An integration interval of $1 \mathrm{~Hz}$ is considered here, and its result is presented in the rightmost column in Table 5 .

The closed-loop controller used in the test is de-

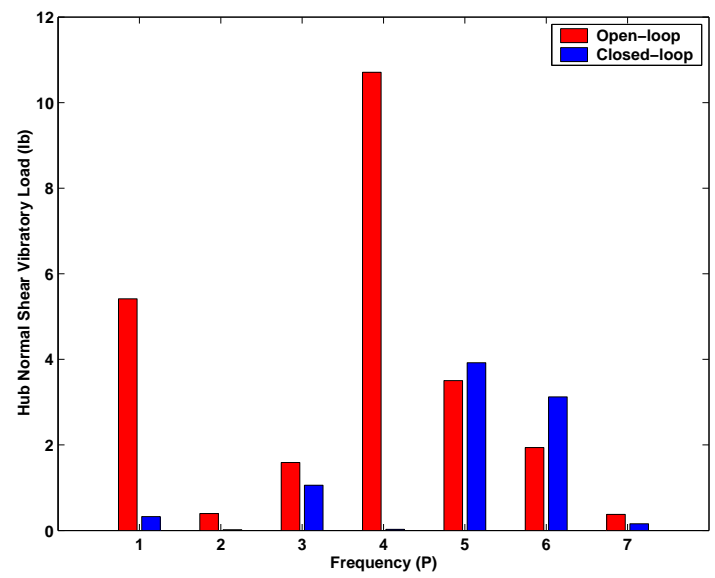

Figure 10: Reduction of the ATR hub vertical shear vibratory load at each discrete integer/rev frequency at $\mu=0.267$

signed for the attenuation of the ATR hub vertical shear vibratory load only. However, the other components of the fixed-system loads, such as axial shear force, sideward shear force, are also reduced by the same controller. The largest simultaneous reduction is obtained in the case CollCyc4, which coincides with the biggest reduction in the hub vertical component. This is illustrated in Fig. 11. The simultaneous reduction is consistent with the ATR open-loop control test results [15]. Further reduction on the different components is expected with multi-component controllers.

Table 5: ATR 4P hub vertical vibration reduction result

\begin{tabular}{||c|c|c|c||}
\hline $\begin{array}{c}\text { Case } \\
\text { name }\end{array}$ & $\begin{array}{c}\text { Open-loop } \\
\text { rms value } \\
(\mathrm{lb})\end{array}$ & $\begin{array}{c}\text { Closed-loop } \\
\text { rms value } \\
(\mathrm{lb})\end{array}$ & $\begin{array}{c}\text { Reduction } \\
\text { performance } \\
(\mathrm{dB})\end{array}$ \\
\hline Cyc1 & 22.35 & 13.77 & -4.20 \\
Cyc2 & 22.45 & 15.14 & -3.42 \\
Cyc3 & 22.52 & 12.06 & -5.42 \\
Cyc4 & 22.55 & 8.87 & -8.10 \\
Cyc5 & 22.61 & 7.19 & -9.94 \\
CollCyc1 & 22.60 & 12.21 & -5.35 \\
CollCyc2 & 22.50 & 8.75 & -8.20 \\
CollCyc3 & 22.26 & 7.60 & -9.33 \\
CollCyc4 & 10.71 & 0.03 & -40.04 \\
CollCyc5 & 10.63 & 0.04 & -38.97 \\
CollCyc6 & 14.06 & 1.41 & -19.96 \\
CollCyc7 & 14.01 & 0.36 & -31.12 \\
CollCyc8 & 21.45 & 10.15 & -6.50 \\
CollCyc9 & 21.35 & 8.72 & -7.77 \\
\hline
\end{tabular}

\section{CONCLUDING REMARKS}



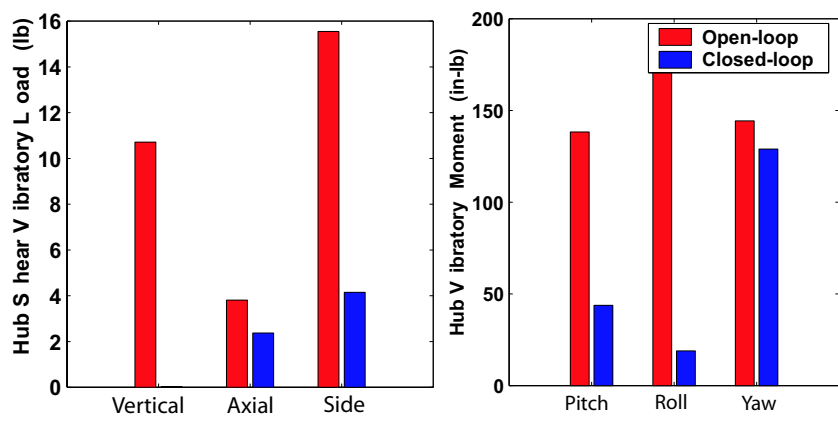

Figure 11: Reduction of the ATR fixed-system load at $4 \mathrm{P}$ frequency at $\mu=0.267$

This paper addresses helicopter performance and vibration improvement using integral blade twist control. First, system identification test is conducted to estimate the control authority exerted upon the rotor system by the blade twist actuation. It is determined that the linear time-periodic system can be represented by a linear time-invariant system under several modes of blade actuation: collective, longitudinal cyclic, and lateral cyclic. Therefore, further controller design and its preliminary evaluation are conducted based on LTI system theory. Significant control authority was observed from the ATR system identification test. Numerical simulation was conducted to study helicopter performance improvement. Steady actuation was used for hover payload increase and $2 \mathrm{P}$ IBC prescribed signal for rotor power reduction in forward flight. Traditional $\mathrm{HHC}$ and its $\mathrm{T}$ matrix approach were used to build a vibration-minimizing controller. Nichols plot is employed for improving controller gain margin by phase shifting. For the ATR hub vertical shear vibratory load control, two cyclic modes at $4 \mathrm{P}$ and collective at $1 \mathrm{P}$ were used. Different combinations of gain constant for each blade actuation mode were tested at different advance ratios. Significant hub normal shear vibratory load reduction is obtained at the target frequencies $(1 \mathrm{P}$ and $4 \mathrm{P})$ in all the test conditions. The maximum experimentally verified vibration reduction was approximately $40 \mathrm{~dB}$. The other components in the fixed-system loads are also reduced at $4 \mathrm{P}$ although only the vertical component is targeted by the controller.

\section{ACKNOWLEDGMENTS}

The authors are especially thankful to Mr. Matthew L. Wilbur, Mr. William T. Yeager, Ms. Renee C. Lake, and Mr. Chester W. Langston (U.S. Army Vehicle Technology Directorate, NASA Langley Research Center) for their support in conducting all the wind-tunnel tests, and to Prof. Steven
R. Hall (Aeronautics and Astronautics, MIT) for his help with the system identification and the closed-loop methodology.

\section{REFERENCES}

[1] Bielawa, R., Rotary Wing Structural Dynamics and Aeroelasticity, American Institute of Aeronautics and Astronautics, 1992.

[2] Shaw, J., N., Albion, J., Hanker E., and Teal, R. S., "Higher Harmonic Control: Wind Tunnel Demonstration of Fully Effective Vibratory Hub Force Suppression," Journal of the American Helicopter Society, Vol. 31, No. 1, 1989, pp. 14-25.

[3] Ham, N. D., "Helicopter Individual-Blade-Control Research at MIT 1977-1985," Vertica, Vol. 11, No. 1/2, 1987, pp. 109-122.

[4] Wood, E. R., Powers, R. W., Cline, J. H., and Hammond, C. E., "On Developing and Flight Testing a Higher Harmonic Control System," Journal of the American Helicopter Society, Vol. 30, No. 1, 1985, pp. 3-20.

[5] Hammond, C. E., "A Unified Approach to the Optimal Design of Adaptive and Gain Scheduled Controllers to Achieve Minimum Helicopter Rotor Vibration," Journal of the American Helicopter Society, Vol. 28, No. 2, 1983, pp. 9-18.

[6] Molusis, J. A., Hammond, C. E., and Cline, J. H., "Wind Tunnel Results Showing Rotor Vibratory Loads Reduction Using Higher Harmonic Blade Pitch," Journal of the American Helicopter Society, Vol. 28, No. 1, 1983, pp. 10-15.

[7] Shaw, J. and Albion, N., "Active Control of the Helicopter Rotor for Vibration Reduction," Journal of the American Helicopter Society, Vol. 26, No. 3, 1981, pp. 32-39.

[8] McHugh, F. J. and Shaw, J., "Helicopter Vibration Reduction with Higher Harmonic Blade Pitch," Journal of the American Helicopter Society, Vol. 23, No. 4, 1978, pp. 26-35.

[9] Jacklin, S. A., Blaas, A., Teves, D., and Kube, R., "Reduction of Helciotper BVI Noise, Vibration, and Power Consumption Through Individual Blade Control," In Proceedings of the American Helicopter Society 51st Annual Forum, Fort Worth, TX, May 9-11 1995. 
[10] Nguyen, K., Betzina, M., and Kitaplioglu, C., "Full-Scale Demonstration of Higher Harmonic Control for Noise and Vibration Reduction on the XV-15 Rotor," In Proceedings of the American Helicopter Society 56th Annual Forum, Virginia Beach, VA, May 2-4 2000.

[11] Loewy, R. G., "Recent Developments in Smart Structures with Aeronautical Applications," In Proceedings of the 37th Israel Annual Conference on Aerospace Sciences, February 26-27 1997.

[12] Friedmann, P. P., "The Promise of Adaptive Materials for Alleviating Aeroelastic Problems and Some Concerns," In Proceedings of Innovation in Rotorcraft Technology, London, United Kingdom, June 24-25 1997, Royal Aeronautical Society, pp. $10.1-10.16$.

[13] Chopra, I., "Status of Application of Smart Structures Technology to Rotorcraft Systems," Journal of the American Helicopter Society, Vol. 45, No. 4, 2000, pp. 228-252.

[14] Rodgers, J. P. and Hagood, N. W., "Development of an Integral Twist-Actuated Rotor Blade for Individual Blade Control," AMSL \# 98-6, Massachusetts Institute of Technology, October 1998.

[15] Wilbur, M. L., Mirick, P. H., Yeager, Jr. W. T., Langston, C. W., Cesnik, C. E. S., and Shin, S.J., "Vibratory Loads Reduction Testing of the NASA/ARMY/MIT Active Twist Rotor," Journal of the American Helicopter Society, Vol. 47, No. 2, 2002, pp. 123-133.

[16] Prechtl, E. F. and Hall, S. R., "An X-frame Actuator Servo-Flap Actuation System for Rotor Control," In Proceedings of the Society of PhotoOptical and Instrumentation Engineering, volume 3329, April 29-May 1 1998, pp. 309-319.

[17] Depailler, G. and Friedmann, P. P., "Reduction of Vibrations due to Dynamic Stall in Helicopters using an Actively Controlled Flaps," In Proceedings of the AIAA/ASME/ASCE/AHS/ASC 43rd Structures, Structural Dynamics and Materials Conference- Adaptive Structures Forum, Denver, CO, April 2002, AIAA Paper No. 2002-1431.

[18] Derham, R. C. and Hagood, N. W., "Rotor Design Using Smart Materials to Actively Twist Blades," In Proceedings of the American Helicopter Society 52nd Annual Forum, Washington, DC, June 4-6 1996.
[19] Cesnik, C. E. S. and Shin, S.-J., "On the Modeling of Integrally Actuated Helicopter Blades," International Journal of Solids and Structures, Vol. 38, No. 10-13, 2001, pp. 1765-1789.

[20] Wilbur, M. L., Yeager, Jr. W. T., Wilkie, W. K., Cesnik, C. E. S., and Shin, S.-J., "Hover Testing of the NASA/ARMY/MIT Active Twist Rotor Prototype Blade," In Proceedings of the American Helicopter Society 56th Annual Forum, Virginia Beach, VA, May 2-4 2000.

[21] Cesnik, C. E. S., Shin, S.-J., and Wilbur, M. L., "Dynamic Response of Active Twist Rotor Blades," Smart Materials and Structures-Special Issue on Rotorcraft Applications, Vol. 10, 2001, pp. $62-76$.

[22] Wereley, N. M. and Hall, S. R., "Linear Time Periodic Systems: Transfer Functions, Poles, Transmission Zeros and Directional Properies," In Proceedings of the 1991 American Control Conference, Boston, Massachusetts, June 26-28 1991.

[23] Bauchau, O. A., "Computational Schemes for Flexible, Nonlinear Multi-Body Systems," Multibody System Dynamics, Vol. 2, 1998, pp. 169-225.

[24] Peters, D. A. and He, C. J., "Finite State Induced Flow Models Part II: Three-Dimensional Rotor Disk," Journal of Aircraft, Vol. 32, No. 2, 1995, pp. 323-333.

[25] Siddiqi, A. and Hall, S. R., "Identification of the Harmonic Transfer Functions of a Helicopter Rotor," AMSL \# 01-01, Massachusetts Institute of Technology, March 2001.

[26] Shin, S.-J. and Cesnik, C. E. S., "Helicopter Vibration Reduction in Forward Flight using Blade Integral Twist Control," In Proceedings of the 43rd AIAA Structures, Structural Dynamics, and Materials Conference, Denver, Colorado, April 22-25 2002, AIAA Paper 2002-1447.

[27] Padfield, G. D., Helicopter Flight Dynamics: The Theory and Application of Flying Qualities and Simulation Modeling, American Institute of Aeronautics and Astronautics, 1996. 